\title{
The Hollywood smile
}

We so often hear patients asking for the film star makeover but Stephen

\section{Hancocks' chat with dental nurse Maureen provides a caution on being} careful what we wish for.

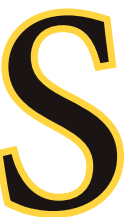

he came into the practice one day in spring. It was one of those 'good to be alive days' when the sun shines, the bulbs are beginning to pop through with bright colours and the air smells fresh and clean after winter's dreariness.

In her early thirties, always pleasant but only an occasional visitor to the practice for check-ups, it would be rather unkind to say that she hadn't made the best of herself but, frankly, she hadn't made the best of herself. This particular day she breezed into the surgery, sat down cool as you like in the chair and announced that she didn't care what it cost but she wanted a Hollywood smile. Well, Dr McKency (my dentist) looked quite amused, only for a fleeting moment you understand and only because I know how he looks when he's fleetingly amused; the patient would never have known. Then he smiled and said something like, 'I see, well we'll have to see what we can do.' I have to admit that what he did for her was amazing and to say that she was delighted is the understatement of the year.

You'll never believe what happened next. It seems that she had put her name forward to be famous, or auditioned, or whatever you have to do and had been snapped up
(I think that's the right expression) for a sequel to Breakfast at Tiffany's which was going to be called Lunch at Prada, and got the part. About a week later Cheryl from Bloomquick the Florists delivered the most enormous flower arrangement I've ever seen, as a thank you. Then a large box of chocolates

'She asked what it would cost to have all her teeth out and rat

\section{a denture made}

\section{to look like her}

\section{previous teeth...'}

arrived and two bottles of champagne. I don't what happened to these. It was all over the local paper and she even said we could include it in the practice newsletter, which Dr McKency said he thought was a good idea and to get more printed than usual as it would be good publicity. She moved to

a big mansion out of town on the moors road, bought a posh sports car

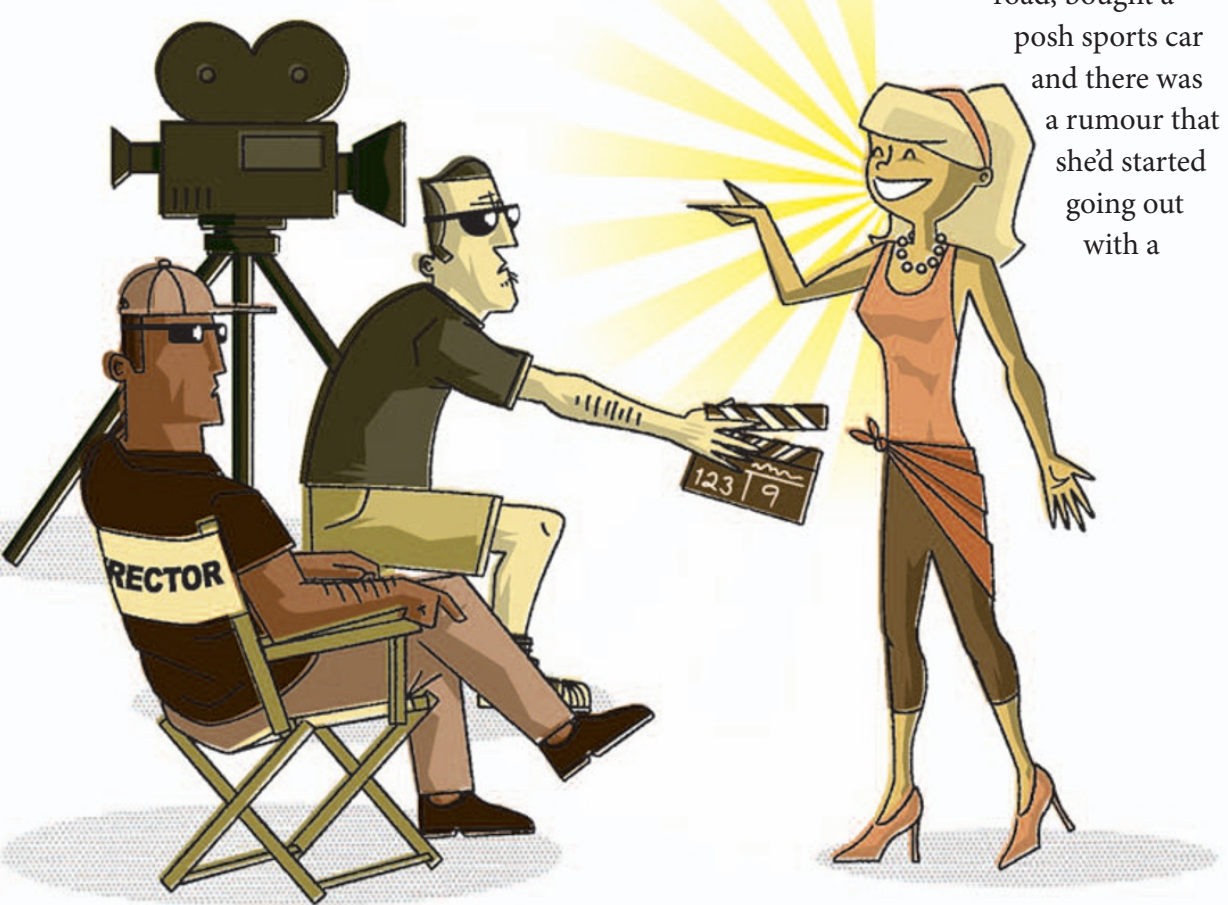

footballer from Fulham, although when I said his name to my boyfriend Glen he snorted and said he was only in the reserves. Anyway it all seemed to be going well and we were pleased that it had all been because of her new smile.

Apparently it was when she was on location in Malaysia that she got bitten by something and her face swelled up to the size of a balloon. I'm not sure what it was but she collapsed and in falling chipped one of her front crowns. The film company was going to get it fixed there and then but she insisted that only Dr McKency could deal with it and that they'd have to fly her back to see us. Imagine! Anyway she was too sick to travel, thanks to the bite going septic and as the production budget only allowed three more days' shooting they wrote her out of those scenes.

I think that must have been where it all started to go wrong. When she got back home the footballer had had this huge party in the mansion and the guests had trashed it (Glen said he wasn't surprised as reserves often get ideas above themselves) and to make matters worse the car had been crashed and drugs left all over the front seats.

The next time she came in she marched straight up to Dr McKency and asked what it would cost to have all her teeth out and a denture made to look like her previous teeth; a bit stained and crooked and more normal. Dr McKency explained that it he couldn't do that ethically as the GDC might take a dim view of it, her being in the limelight and all. He suggested that smoking a bit more and drinking lots of red wine and coffee might do the trick instead. But I could see he was only joking really because I know when he is and anyway he knew she didn't smoke.

So, there it is. She works in the local chippy now and seems quite happy really. She recognises me of course when I go in for a saveloy and chips if Glen's out for the evening (he can't bear saveloys for some reason so I have to have them when he's not there) and she's always very pleasant. I'm sure everyone remembers but they're all too polite to say anything. Oh, and Dr McKency told me to recycle the extra practice newsletters as they won't be much use now. Shame really. 